Supporting Information for

\title{
Realizing Mechanically Robust and Electrically Conductive Wood via Vacuum Pressure Impregnation
}

Xiaotao Zhang ${ }^{a, b, *}$, Guoyan Ning ${ }^{c, *}$, Peng Chen ${ }^{c, t}$, Zhangjing Chen ${ }^{d}$, Yamei Wang ${ }^{c}$, Jianfang Yu ${ }^{c}$,

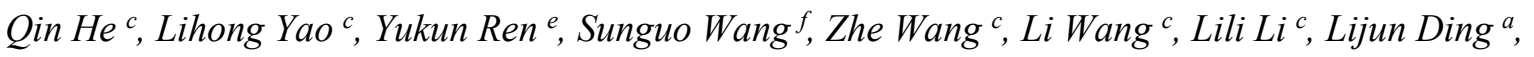
Yinan Hao ${ }^{c, b}$ and Ximing Wang ${ }^{c, b, *}$

a. College of Science, Inner Mongolia Agricultural University, Hohhot, P.R. China.

b. Inner Mongolia Key Laboratory of Sandy Shrubs Fibrosis and Energy Development and Utilization.

c. College of Material Science and Art Design, Inner Mongolia Agricultural University, Hohhot, P.R. China.

d. Department of Sustainable Biomaterials Virginia Tech University, Blacksburg, VA, USA.

e. Bioimaging Research, Sanofi Global R\&D, Framingham, MA,USA.

f. Sungro Bioresource \& Bioenergy Technologies Corp, Alberta, Canada.

* Corresponding author: Ximing Wang (E-mail: wangximing@imau.edu.cn)

$\uparrow$ Contributed equally to this paper. 


\section{Optimization of Synthesis Process}
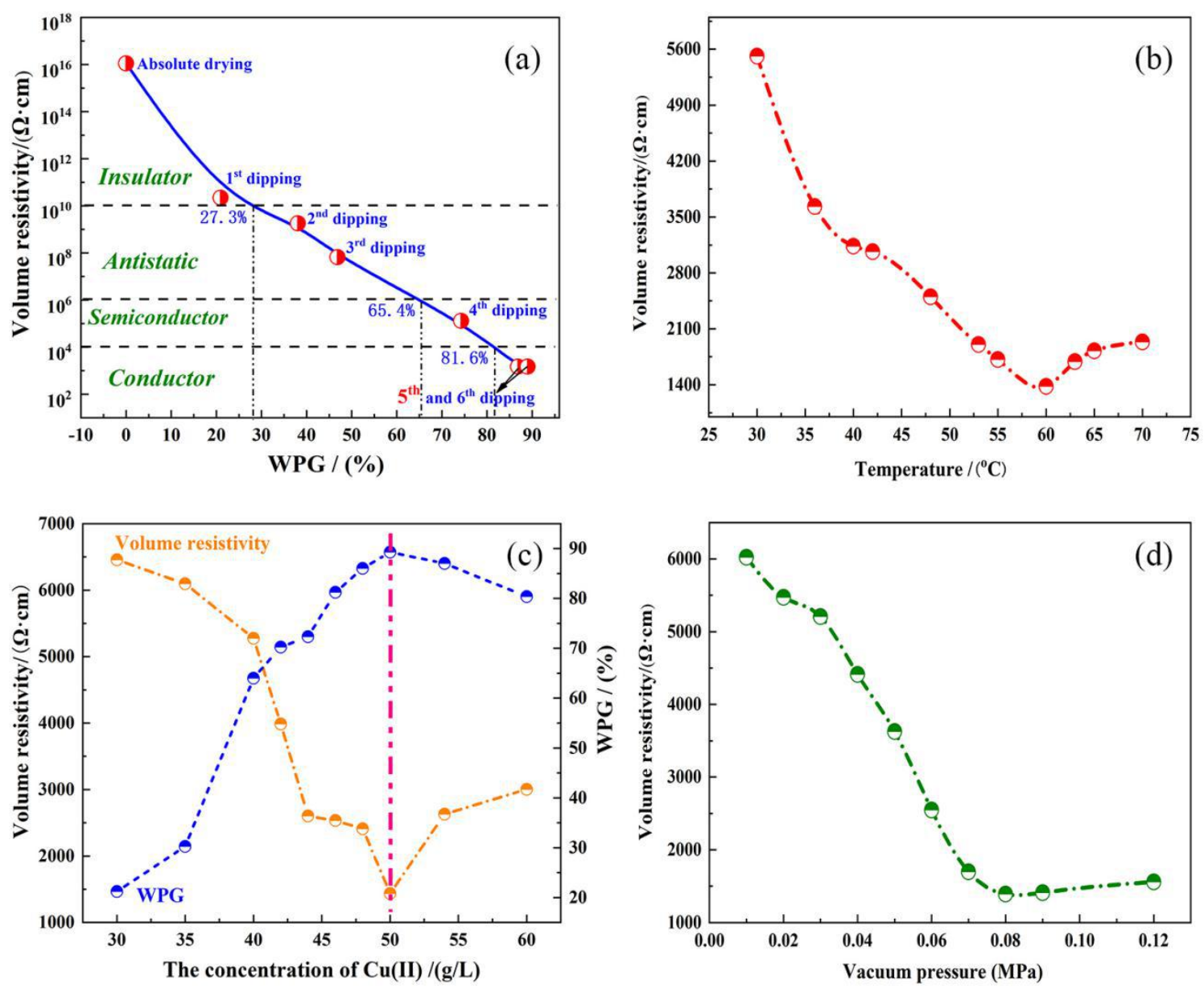

Figure S1. a) Effects of the WPG values on the volume resistivity of Cu-SW. (Dipping experiments--vacuum pressure: $0.08 \mathrm{MPa}$, temperature: $60{ }^{\circ} \mathrm{C}, \mathrm{Cu}(\mathrm{II})$ concentration: $50 \mathrm{~g} / \mathrm{L}$ ), b) Effects of temperature on the volume resistivity of Cu-SW. (Dipping experiments--vacuum pressure: $0.08 \mathrm{MPa}$, dippings times: 5, $\mathrm{Cu}(\mathrm{II})$ concentration: $50 \mathrm{~g} / \mathrm{L})$, c) Effects of the concentration of $\mathrm{Cu}(\mathrm{II})$ on the volume resistivity and WPG of Cu-SW. (Dipping experiments-vacuum pressure: $0.08 \mathrm{MPa}$, dippings times: 5, temperature: $60^{\circ} \mathrm{C}$ ). d) Effects of vacuum pressure on the volume resistivity of $\mathrm{Cu}-\mathrm{SW}$. (Dipping experiments--temperature: $60{ }^{\circ} \mathrm{C}$, dippings times: 5, $\mathrm{Cu}(\mathrm{II})$ concentration: $50 \mathrm{~g} / \mathrm{L})$. 


\section{Effect of WPG on volume resistivity}

Weight Percentage Gain (WPG) is an important parameter for evaluating the improvement in the quality of resins or other fillings in woods, usually represents the impregnation effect of wood sample. The WPG of wood was calculated according to the following equation (1).

$$
W P G=\frac{\left(W_{2}-W_{1}\right)}{W_{1}} \times 100 \%
$$

where $W_{1}$ and $W_{2}$ are the oven-dried weights of the sample before and after the drying operation $(\mathrm{g})$, respectively. Taking into account the experimental errors and based on the average values, eight independent replicates confirmed that the results of the volume resistivity were reproducible in parallel under the same conditions and that the reproducibility of the result was within $\pm 3 \%$.

The relationship between the WPG and the volume resistivity of $\mathrm{Cu}-\mathrm{SW}$ is discussed as shown in Figure S1a. It can be seen from Figure S1a that the volume resistivity was highly WPG dependent because the continuous and dense conductive network for electron hopping/migrating is greatly affected by WPG. The electrical conductivity of sample can be classified by the volume resistivity: when the volume resistivity exceeds $10^{10} \Omega \cdot \mathrm{cm}$, it is insulator, when the volume resistivity value is between $10^{6} \Omega \cdot \mathrm{cm}$ and $10^{10} \Omega \cdot \mathrm{cm}$, it is antistatic conductor, when the volume resistivity is between $10^{4} \Omega \cdot \mathrm{cm}$ and $10^{6} \Omega \cdot \mathrm{cm}$, it is semiconductor, and when the volume resistivity value is less than $10^{4} \Omega \cdot \mathrm{cm}$, it is conductor [S1]. As noted above, it can be indicated from Figure S1a that 27.3\% WPG confidence level is the demarcation point between insulator and antistatic conductor, 65.4\% WPG confidence level is the cut-off point between antistatic conductor and semiconductor, and $81.6 \%$ WPG confidence level is the demarcation between semiconductor and conductor. According to the 
values of WPG, Figure S1a also clearly presented that the number of vacuum pressure impregnation substantially influenced the volume resistivity, which decreased sharply as the number of impregnation increased from $1.102 \times 10^{16} \Omega \cdot \mathrm{cm}$ (absolute drying state) to $1.366 \times 10^{3} \Omega \cdot \mathrm{cm}$ (the fifth dipping times), and until equilibrium but hardly increased. This result can be attributed to the fact that the chemical bonding, electrostatic interaction, coordination and chelation interaction between $\mathrm{Cu}(\mathrm{II})$ ions that filled inside and grown on the curved inner wall of the wood cells, and $-\mathrm{OH},-\mathrm{C}=\mathrm{O},-\mathrm{COOH}$ and other oxygen-containing functional groups existed in the polymer chains of wood components, which was formed a continuous carrier pathway along the alignment direction inside $\mathrm{Cu}-\mathrm{SW}$ structure, which provided a ascending space for the carrier mobilities of $\mathrm{Cu}(\mathrm{II})$ ions, leading to improve the effective conductivity and reduce the conductive thresholds. When it is the $5^{\text {th }}$ dippings, the volume resistivity reached the minimum amount of $1.366 \times 10^{3} \Omega \cdot \mathrm{cm}$. Hence, the optimal number of impregnation to obtain conductivity $\mathrm{Cu}-\mathrm{SW}$ in this work is 5 .

\section{Effect of temperature on volume resistivity}

Figure S1b shows the relationship between the temperature of vacuum pressure impregnation and the volume resistivity of $\mathrm{Cu}-\mathrm{SW}$. The temperature here refers to the vacuum pressure impregnation temperature when the poplar wood samples were immersed in cupric sulfate, potassium solidium tartrate, ethylene diamine tetraacetic acid and sodium hypophosphite $(\mathrm{Cu}$ (II)-TART-EDTA-SH) solution in the Vacuum Chamber (DZF-2ASB, Beijing, China). The volume resistivity of $\mathrm{Cu}-\mathrm{SW}$ greatly reduced from $5.512 \times 10^{3} \Omega \cdot \mathrm{cm}$ to $1.517 \times 10^{3} \Omega \cdot \mathrm{cm}$ with increasing temperature from $60^{\circ} \mathrm{C}$. The reason for this phenomenon maybe $\mathrm{Cu}(\mathrm{II})$-EDTA with catalytic TART, which can promote redox reactions between metal ions and activated functional groups of wood interstructure, in addition, $\mathrm{Cu}$ (II)-EDTA which has different organic monomers, is easily decomposed to produce large amounts of metaloxides during the process of high temperature and vacuum pressure impregnation. When the 
temperature is higher than $60^{\circ} \mathrm{C}$, the $\mathrm{Cu}(\mathrm{II})$-TART-EDTA could be crystallized under certain vacuum pressure, which resulted in a raise in the volume resistivity of $\mathrm{Cu}-\mathrm{SW}$ after $60^{\circ} \mathrm{C}$. Therefore, we determined that the optimum temperature for vacuum pressure impregnation was $60^{\circ} \mathrm{C}$.

\section{Effect of $\mathrm{Cu}(\mathrm{II})$ concentration on volume resistivity}

The effect of $\mathrm{Cu}(\mathrm{II})$ concentration on the volume resistivity was investigated and shown in Figure S1c. It can be seen that volume resistivity of $\mathrm{Cu}-\mathrm{SW}$ sharply reduced from $6.455 \times 10^{3} \Omega \cdot \mathrm{cm}$ to $1.436 \times 10^{3} \Omega \cdot \mathrm{cm}$ with increasing the $\mathrm{Cu}(\mathrm{II})$ concentration from $30 \mathrm{~g} / \mathrm{L}$ to $50 \mathrm{~g} / \mathrm{L}$. Afterwards, the volume resistivity of $\mathrm{Cu}-\mathrm{SW}$ increased to $3.004 \times 10^{3} \Omega \cdot \mathrm{cm}$ with further increasing the concentration of $\mathrm{Cu}(\mathrm{II})$ from $50 \mathrm{~g} / \mathrm{L}$ to $60 \mathrm{~g} / \mathrm{L}$. This phenomenon indicated that aggregation of $\mathrm{Cu}$ (II) ions concentration would be likely facilitated to diffuse $\mathrm{Cu}(\mathrm{II})$ deeper into the internal structure of $\mathrm{Cu}-\mathrm{SW}$ and formed a smooth conduction pathway. Meanwhile, with the increasing of $\mathrm{Cu}(\mathrm{II})$ concentration a complex polymer may be easily produced, crystallized and precipitated. In addition, Figure S1c also shows the effect of the concentration of $\mathrm{Cu}(\mathrm{II})$ on WPG percentage content in wood matrix. It can be clearly seen that the quality of wood increased greatly after vacuum heating/pressure impregnation treatment, indicating that the content of $\mathrm{Cu}$ in poplar wood sample increased correspondingly. When the corresponding concentrations of the precursor $\mathrm{Cu}(\mathrm{II})$ solution were $30,35,40,42$, $44,46,48,50,54,60 \mathrm{~g} / \mathrm{L}$, the WPG of poplar wood sample were calculated to be $21.22 \%$, $30.26 \%, 64.01 \%, 70.25 \%, 72.33 \%, 81.23 \%, 86.04 \%, 89.3 \%, 87.02 \%$, and $80.36 \%$, respectively. Thus, the effects of $\mathrm{Cu}(\mathrm{II})$ concentrations on quality is not linear, The results revealed that when the concentration of $\mathrm{Cu}(\mathrm{II})$ was $50 \mathrm{~g} / \mathrm{L}$, the optimum wettability of poplar wood to the precursor solution $\mathrm{Cu}(\mathrm{II})$-TART-EDTA was reached, illustrating the WPG and the contents of $\mathrm{Cu}$ in $\mathrm{Cu}-\mathrm{SW}$ reached the maximum value. Comparatively, the optimum $\mathrm{Cu}(\mathrm{II})$ 
concentration of $50 \mathrm{~g} / \mathrm{L}$ was selected for the following experiments of vacuum pressure impregnation.

\section{Effect of vacuum pressure on volume resistivity}

The effect of vacuum pressure on the volume resistivity was shown in Figure S1d. It can be seen that volume resistivity of $\mathrm{Cu}-\mathrm{SW}$ was decreased from $6.023 \times 10^{3} \Omega \cdot \mathrm{cm}$ to $1.391 \times 10^{3} \Omega \cdot \mathrm{cm}$ as vacuum pressure was increased from $0.01 \mathrm{MPa}$ to $0.08 \mathrm{MPa}$. And then, the volume resistivity slowly increased from $1.391 \times 10^{3} \Omega \cdot \mathrm{cm}$ to $1.560 \times 10^{3} \Omega \cdot \mathrm{cm}$ with further increase of vacuum pressure from $0.08 \mathrm{MPa}$ to $0.12 \mathrm{MPa}$. It was observed that the volume resistivity is highly dependent on the vacuum pressure of the fabrication process, which affects the viscosity of the impregnating solution and removal of other substances such as wood extracts, ash, tannins, etc, from internal structure wood. At lower vacuum pressure, the fluidity of the impregnating solution is increased, therefore it is disadvantageous to the efficiency of impregnating. At vacuum pressure above $0.08 \mathrm{MPa}$, the impregnation solution is easy to solidify, the chemical bonds and interactions between $\mathrm{Cu}(\mathrm{II})$ and the active groups of wood components, and the decomposition of organic polymer long chain leading to mineralization. Optimum vacuum pressure was selected as $0.08 \mathrm{MPa}$ for further experiments.
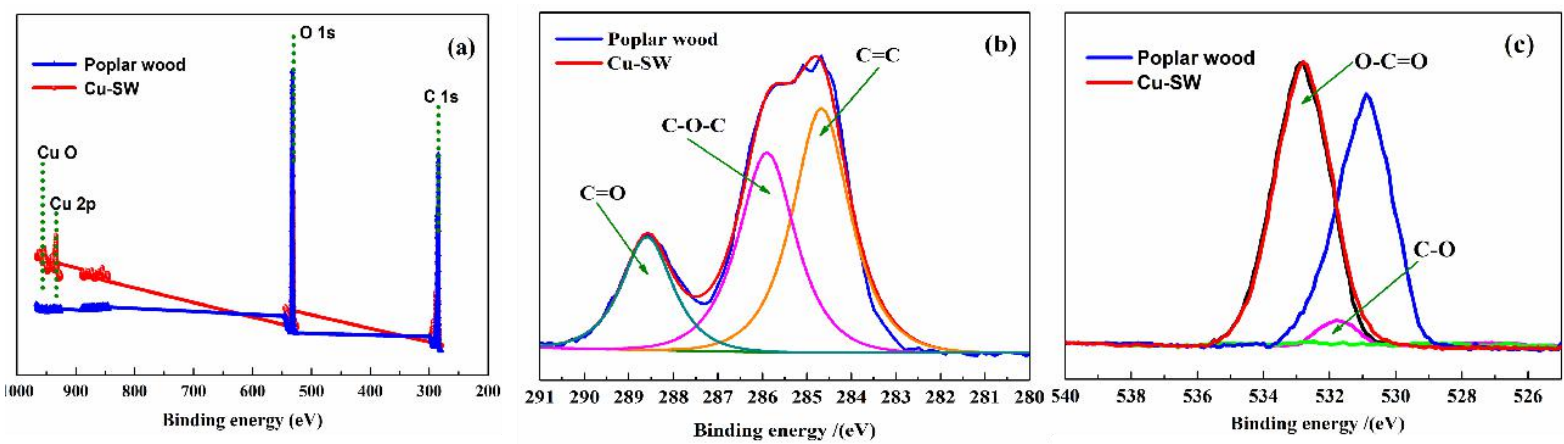

Figure S2. XPS survey scan of poplar wood and Cu-SW. a) Full scan XPS spectra of the poplar wood and Cu-SW. b) C 1s XPS spectra of the poplar wood and $\mathrm{Cu}-\mathrm{SW}$. c) O 1s XPS spectra of the poplar wood and Cu-SW. 
C 1s spectrum of carbon can be deconvoluted into three obvious peaks appeared at 284 $288.8 \mathrm{eV}$, corresponding to the $s p^{2}$ domains $(\mathrm{C}=\mathrm{C}$ with a binding energy of $284-285 \mathrm{eV}$, and the $s p^{3}$ domains $(\mathrm{C}-\mathrm{O}$ with a binding energy of $286 \mathrm{eV}$, and $\mathrm{C}=\mathrm{O}$ with a binding energy of $288 \mathrm{eV}$, respectively). The increase in oxygen bearing groups confirmed the successful infiltration, deposition and chemical cross-link reactions between $\mathrm{Cu}(\mathrm{II})$ and the structures of poplar wood. The binding- $\mathrm{Cu}(\mathrm{II})$ coincided with a significant decrease in $\mathrm{O}$ 1s spectrum peak area (Figure S2). This phenomenon is might be due to the fact that $\mathrm{C}-\mathrm{O}, \mathrm{C}=\mathrm{O}$, and $\mathrm{O}-\mathrm{H}$ in poplar wood is reacted with $\mathrm{Cu}(\mathrm{II})$, involving in chemical-bonding, electrostatic attraction, coordination/chelation and complexation interactions, which can be indicated different kinds of $\mathrm{Cu}$ (II)-Oxygen bondings existed in $\mathrm{Cu}-\mathrm{SW}[\mathrm{S} 2, \mathrm{~S} 3]$.

\begin{tabular}{|c|c|c|}
\hline Sample & Poplar wood & Cu-SW \\
\hline C(at.\%) & 56.93 & 52.54 \\
\hline O(at.\%) & 42.80 & 42.94 \\
\hline N(at.\%) & 0.11 & 1.07 \\
\hline K(at.\%) & $\mathbf{0 . 1 6}$ & 0.19 \\
\hline Cu(at.\%) & --- & 3.26 \\
\hline
\end{tabular}

Figure S3. EDS result for wood and $\mathrm{Cu}-\mathrm{S}$ 


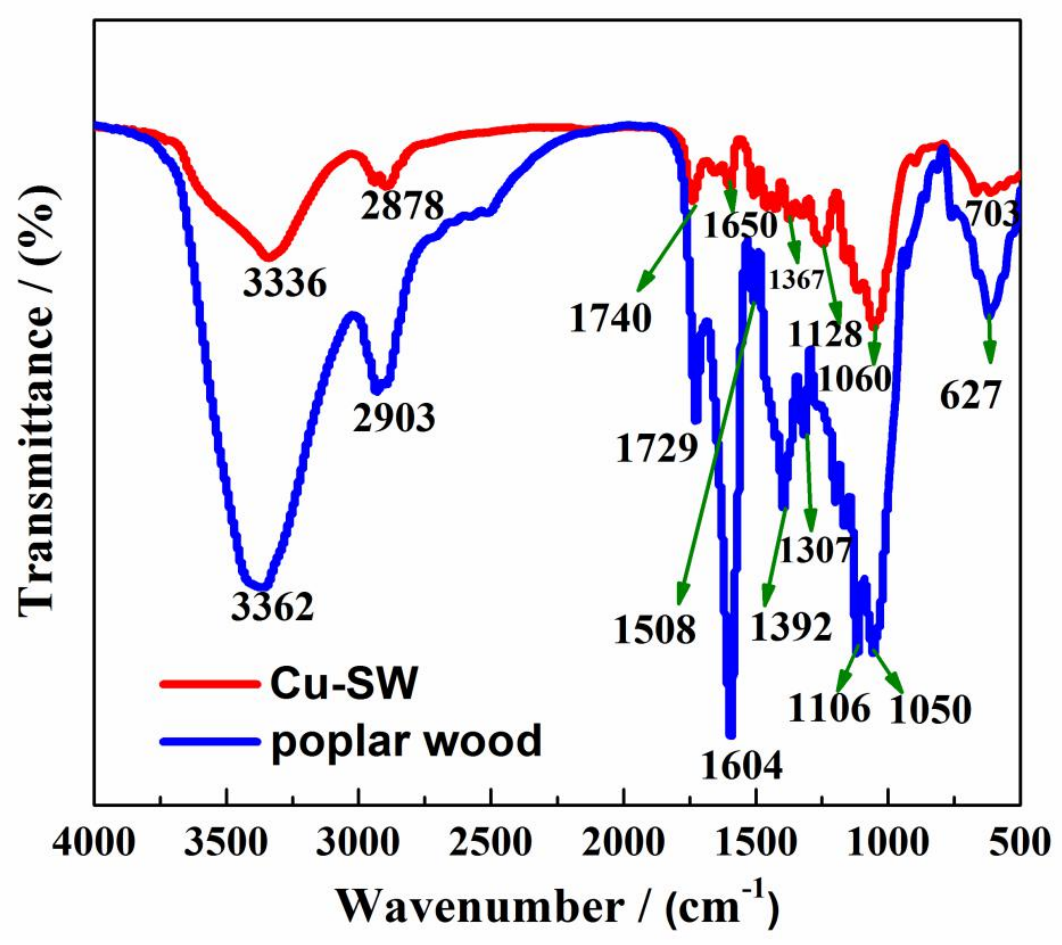

Figure S4. FTIR spectrum of the poplar wood and $\mathrm{Cu}-\mathrm{SW}$.

\section{FTIR analysis}

The surface functional groups of the Cu-SW highly influence its characteristics and the electrical conductivity. The FTIR spectra of the natural poplar wood and the electrical conductive $\mathrm{Cu}-\mathrm{SW}$ were shown in Figure S4. As can be seen, the absorbance band with a peak at $3362 \mathrm{~cm}^{-1}$ attributed to the $\mathrm{O}-\mathrm{H}$ and the corresponding hydrogen bonds of natural poplar wood, shifted to lower wave number $3336 \mathrm{~cm}^{-1}$ and weakened after vacuum pressure impregnation, indicating that the $\mathrm{O}-\mathrm{H}$ and the corresponding hydrogen bonds reacted with $\mathrm{Cu}(\mathrm{II})$. The bands at $2903 \mathrm{~cm}^{-1}$ were related to the $\mathrm{C}-\mathrm{H}$ stretching of methyl groups, which shifted and reduced around $2878 \mathrm{~cm}^{-1}$ after $\mathrm{Cu}(\mathrm{II})$-dippings. The intensity of the peak at approximately $1729 \mathrm{~cm}^{-1}$ revealed the characteristics of the $\mathrm{C}=\mathrm{O}$ stretching in the $-\mathrm{COO}$ groups, which were shifted to higher wave number $1740 \mathrm{~cm}^{-1}$ and greatly lowered after $\mathrm{Cu}(\mathrm{II})$-dippings. Logically, the peaks appearing at $1604 \mathrm{~cm}^{-1}$ were assigned to the $\mathrm{O}-\mathrm{C}=\mathrm{O}$ of carbonyl (e.g., ketone), the intensity of this adsorption band obviously decreased and shifted 
to $1650 \mathrm{~cm}^{-1}$. Furthermore, the band at approximately $1392 \mathrm{~cm}^{-1}$ was ascribed to the Ar-O-C stretching in saturated aliphatic groups and the carboxylate ion (-C-O-) groups shifted and reduced at $1367 \mathrm{~cm}^{-1}$. Adsorption bands that occurred at approximately $1307 \mathrm{~cm}^{-1}$ attributed to the C-H stretching of alcoholic groups, nearly disappeared in conductive $\mathrm{Cu}-\mathrm{SW} .1106 \mathrm{~cm}^{-}$ ${ }^{1}$ and $1050 \mathrm{~cm}^{-1}$ attributed to the $\mathrm{C}-\mathrm{O}$ vibrations of $-\mathrm{C}-\mathrm{O}$ and $-\mathrm{O}-\mathrm{C}=\mathrm{O}$ stretching of the carboxyl groups shifted to $1128 \mathrm{~cm}^{-1}$ and $1060 \mathrm{~cm}^{-1}$. In addition, $627 \mathrm{~cm}^{-1}$ related to $\mathrm{C}-\mathrm{H}$ and $\mathrm{O}-\mathrm{H}$ vibration groups of the aromatic alcohols, increased and shifted to $703 \mathrm{~cm}^{-1}$ after $\mathrm{Cu}(\mathrm{II})-$ dippings. These changes in the characteristic peaks indicated that the activated functional groups, including hydroxyl, carboxylic functional groups, and the free carboxyl groups became carboxylates, which are highly activate sites reacted with $\mathrm{Cu}(\mathrm{II})$ to form new chelated/coordinated chemical-bonding of $\mathrm{O}-\mathrm{Cu}$ and other intermolecular forces, etc. Moreover, the conditions of high temperature under vacuum pressure impregnation could originate some complicated cross-link reactions in the interstructure of $\mathrm{Cu}-\mathrm{SW}$. The results indicated that the alkaline condition of $\mathrm{Cu}(\mathrm{II})$-TART-EDTA-SH complex solutions could be partially hydrolyzed, changing the chemical environments around the functional groups, leading to the dissociation of $\mathrm{Cu}(\mathrm{II})$-TART-EDTA in poplar wood, promoting the reactions of $\mathrm{Cu}(\mathrm{II})$ and activated the functional groups of wood molecules. Generally, the information observed from FTIR spectra suggested that chelated/coordinated chemical-bonding and intermolecular interactions, etc, were formed between $\mathrm{Cu}(\mathrm{II})$ and $-\mathrm{OH},-\mathrm{C}=\mathrm{O}$, and $-\mathrm{O}-\mathrm{C}=\mathrm{O}$ groups, meanwhile, the percentage content of $\mathrm{Cu}(\mathrm{II})$ have an important influence on the conductive effects [S4].

\section{References}

[S1] Wen, J.; Li, J.; Chen, Q. Y. Preparation of copper nanoparticles with liquid reduction method by sodium hypophosphite. J. Funct. Mater. 2011, 42, 189-192. DOI: 10.1631/jzus.A1000257. 
[S2] Huang, J.; Zhang, S.; Zhang F.; Guo, Z.; Jin, L.; Pan, Y.; Wang, Y.; Guo T. Enhancement of lignocellulose-carbon nanotubes composites by lignocellulose grafting. Garbohyd. Polym. 2017, 160, 115-122. DOI:10.1016/j.carbpol.2016.12.053.

[S3] William, H.; David, T.; Li, Y.; Li, Y.; Pei, A.; Chen, H.; Cui, Y. Nanostructural and electrochemical evolution of the solid-electrolyte interphase on $\mathrm{CuO}$ nanowires revealed by cryogenic electron microscopy and impedance spectroscopy. ACS Nano. 2019, 13, 737-744. DOI: 10.1021/acsnano.8b08012.

[S4] Liu, Ao.; Zhi, H.; Park, W-T.; Kang, S-J.; Xu, Y.; Kim, M-G,; Noh, Y-Y. Roomtemperature solution-synthesized p-type copper(I) lodide semiconductors for transparent thin-film transistors and complementary electronics. Adv. Mater. 2018, 23, 1802379. DOI: $10.1002 /$ adma.20180237 